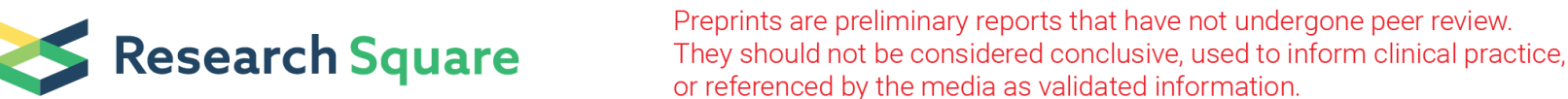

\section{Evaluation of the Relationship Between Vitamin D Levels and Related Serum Markers as Well as Disease Activity in Patients With Rheumatoid Arthritis: A Cross-sectional Study in Western Iran}

\section{Nasrin Moghimi}

Kurdistan University of Medical Sciences

Ali Faridfar

Kurdistan University of Medical Sciences

Reza Shahriarirad

Shiraz University of Medical Sciences

Mohsen Nikandish

Shiraz University of Medical Sciences

Amirhossein Salimi

Shahid Sadoughi University of Medical Sciences and Health Services: Shahid Sadoughi University of

Medical Sciences and Health Services

Maryam Salimi ( $D$ salimimaryam7496@gmail.com )

Shiraz University of Medical Sciences https://orcid.org/0000-0001-9771-7048

\section{Research}

Keywords: Anti cyclic citrullinated peptide antibody, rheumatoid arthritis, vitamin D, 25-hydroxyvitamin D, rheumatoid factor

Posted Date: December 18th, 2020

DOl: https://doi.org/10.21203/rs.3.rs-125995/v2

License: (c) (i) This work is licensed under a Creative Commons Attribution 4.0 International License. Read Full License 


\section{Abstract}

Introduction: Many studies have reported the role of vitamin D in rheumatoid arthritis (RA) which is related to several serum autoantibodies such as RF and Anti CCP. It also has been shown that vitamin D deficiency affect the DAS28 and VAS score inversely. Therefore, we aim to assess the relationship between vitamin D deficiency and RA-related autoantibodies including Anti CCP and RF levels and also evaluate the association between these parameters and the severity of disease.

Methods: In this cross-sectional study, RA patients over 16 years of age were enrolled. The severity of diseases was assessed via the DAS28 scoring system. Serum levels of $25(\mathrm{OH})$ vitamin D were determined by the ELISA method, along with other rheumatoid related laboratory evaluations including Anti CCP, RF and CRP

Results: A total of 100 patients with a mean age of $45.27 \pm 14.14$ were included and evaluated; of them, $75 \%$ were female and $77 \%$ lived in the city. Most of the patients (66\%) had moderate DAS28 levels; however, no substantial relationship was observed between DAS28 and vitamin D levels. A significant positive relation between serum $25(\mathrm{OH}) \mathrm{D}$ level and disease duration, as well as the level of education, was observed. There was also no significant correlation between RA-related autoantibodies and inflammatory serum marker with 25(OH)D.

Conclusion: Due to vitamin deficiency in the majority of cases (73\%) and the relationship between serum 25(OH)D levels and the duration of disease, it can be concluded that vitamin D levels should be checked in those patients.

\section{Key Points}

- Anti-CCP and RF are the autoantibodies which present in the serum of RA patients and sometimes were considered as a prognostic factor in these patients.

- 25-hydroxyvitamin D which was measured to evaluate the level of serum vitamin D and lower level of the foregoing vitamin was considered as an inclination factor for disclosure of RA symptoms in susceptible patients.

- DAS28 score is a measure of disease activity in RA patients and also was claimed to has a negative association with vitamin D levels

\section{Introduction}

Rheumatoid arthritis (RA), as a chronic and systemic polyarticular arthritis, affects approximately $1 \%$ of the population and predominantly females. Furthermore, the prevalence increases with age and is more common in the fourth and fifth decades of life $[1,2]$. The disease presents itself with systemic polyarthritis as well as extra-articular manifestation including rheumatoid nodules, pulmonary fibrosis, vasculitis, and serositis. Moreover, the course of RA is highly variable and unpredictable for each patient. 
Mostly, the disease activity is continuous and alters at the same time, with varying degrees of joint deformities and functional disorders [3].

Antibodies against cyclic citrullinated peptides (CCP) and rheumatoid factor (RF) have been identified in studies based on the serological examination of RA patients; while they have about the same susceptibility, they have been documented to have higher specificity for anti-CCP. These RA-related autoantibodies are also specifically associated with the prognosis of the disorder [4,5].

The pathogenesis of autoimmune diseases including RA depends on the environmental and genetic factors. In this regard, vitamin $D$ has been identified as a pathogenetic factor for autoimmune disorders such as multiple sclerosis and type 1 diabetes [6]. Specifically, after the discovery of its receptors in the cells linked to the immune system, the regulatory function of vitamin D was proposed. Activated dendritic cells have also been proven to develop hormones linked to vitamin $\mathrm{D}$ which inhibits the proliferation of $T$ cells, especially Th1 and the production as well as secretion of antibodies, inflammatory cytokines, and B cells. It also differentiates the monocytes from dendritic cells, interacting in vitro with the activity of $T$ cells $[7,8]$. Higher doses of vitamin D are associated with a reduced incidence of rheumatoid arthritis, and lower vitamin $\mathrm{D}$ levels are associated with a greater severity of the condition, according to the literature. In addition, lower levels of 25-Hydroxy Vitamin D (25(OH)D), as a prehormone formed in the liver and as a metabolite evaluated by physicians worldwide to ascertain a patient's vitamin $D$ status, have been found in RA patients who have not been in the recovery process or who have not reacted to treatment; also, the activity of the disease, usually assessed by joint swelling and tenderness, inflammation, and

Hypovitaminosis D will also increase the number of swollen and sore joints as well as the amount of CRP, thus aggravating the self-assessment of the patient's health [9-12].

Based on the literature, the disease activity is associated with serum RA-related autoantibodies levels including RF and anti-CCP [13]. on the other hand, hypovitaminosis D may elevate the disease activity. Therefore, hypovitaminosis $\mathrm{D}$ may be in association with the level of the mentioned autoantibodies. Furthermore, studies in this regard are limited. Therefore, this study was conducted to evaluate the relationship between vitamin D insufficiency and serum RF and anti-CCP levels and also its association with the severity of rheumatoid arthritis to provide better evidence in the management of these patients.

\section{Materials And Methods}

In this cross-sectional study, patients aged 16 years and above referring to the rheumatological clinic of Tohid hospital from April to September 2015 with a diagnosis of RA based on the guidelines of the American College of Rheumatology (ACR) were included [14]. Patients who had a history of recent vitamin $D$ supplement use in the previous 3 months were excluded from our study. The sample size was calculated based on a study by Soubrier et al. [15]. By considering a standard deviation of 0.45 , power of $90 \%$ to detect a difference in HAQ (primary outcome) of at least 0.24 , we reached a sample size of 74 patients. Also, by considering a two-sided type-I error at 0.05 , a total sample size of 82 patients was calculated. The obtained data consisted of the patient's demographic information and comorbid diseases 
along with their RA disease features such as duration of the onset of symptoms, morning stiffness, number of joints involved, radiological changes due to RA, rheumatoid nodule, serum levels of RF, and CRP.

The patients were then examined by a single expert rheumatologist who was blinded about the patients' paraclinical data. Evaluation of patients was based on DAS28 and a cut-off point of above 2.6 for active RA disease, while less than 2.6 was considered as remission and responsive to RA treatment.

For the assessment of the pain severity in the patients, the Visual Analogue Scale system (VAS), a $10 \mathrm{~cm}$ scaled ruler was used to show the degree of pain in these patients, such that 0 and 10 were its two extremes representing no pain and worst pain, respectively. Furthermore, 1-3 score denoted relative pain, 4-6 moderate pain, and 7-10 severe pain overall [16]. Several internationally published papers have confirmed the reliability and durability of the VAS scale $[17,18]$, and many Iranian national publications confirmed its durability with a correlation coefficient of R: 0.88 [19].

Additionally, 2cc blood was obtained and sent to the laboratory. The samples were evaluated by a single laboratory technician who was blinded about the patient's data. For determining the vitamin D's serum levels, an ELISA kit (Euroimmun Kit, Nima Pooyesh Teb Company, Tehran, Iran) was utilized [20]. Also, Anti CCP, RF, and CRP levels of the samples were measured.

The patient's demographic, clinical, and paraclinical data were analyzed using SPSS version 22.0 software. Spearman coefficient was used to evaluate the relationship between the variables. A P value of lower than 0.05 was assigned as significant.

\section{Results}

A total of 100 participants fulfilled the inclusion criteria and were followed till the end of our study. Males constituted $25 \%$ of RA cases, while $75 \%$ of the cases were female. The mean age of the participants was 45.27 years (SD: 14.14, range 20 - 87). Among them, the majority (77\%) were from urban areas, while most of the cases were also illiterate (43\%). Table 1 demonstrates the demographic features of the patients in our study.

Table 1 Demographic and clinical features of rheumatoid arthritis patients and their correlation with 25(OH)D levels 


\begin{tabular}{|c|c|}
\hline Variable & Frequency $n=100$ \\
\hline \multicolumn{2}{|l|}{ Gender } \\
\hline Male & 25 \\
\hline Female & 75 \\
\hline \multicolumn{2}{|l|}{ Residence } \\
\hline Urban & 77 \\
\hline Rural & 23 \\
\hline \multicolumn{2}{|l|}{ Occupation } \\
\hline Housewife & 60 \\
\hline Public employee & 17 \\
\hline Unemployed & 8 \\
\hline Manual worker & 4 \\
\hline Freelance & 5 \\
\hline Farmer & 3 \\
\hline Retired & 3 \\
\hline \multicolumn{2}{|l|}{ Education } \\
\hline Illiterate & 43 \\
\hline Under-Diploma & 28 \\
\hline Diploma & 16 \\
\hline Bachelors and masters & 13 \\
\hline \multicolumn{2}{|l|}{ 25(OH)vitamin D } \\
\hline Deficient & 29 \\
\hline Insufficient & 44 \\
\hline Optimal & 27 \\
\hline \multicolumn{2}{|l|}{ DAS28 ${ }^{\mathrm{a}}$ score } \\
\hline Mild & 21 \\
\hline Moderate & 66 \\
\hline Severe & 13 \\
\hline${ }^{\mathrm{a}}$ : disease activity score & \\
\hline
\end{tabular}

As Table 1 demonstrates, the majority (73\%) had either insufficient or deficient serum levels of vitamin D. The average level of 25(OH)D was $24.17 \mathrm{ng} / \mathrm{mL}$. Based on the spearman coefficient analysis between the serum levels of 25(OH)D and DAS28 score, there was no significant correlation among these two groups (Table 2). Also, $66 \%$ of the patients had a moderate level of DAS28 (2.6-3.2), which were not in remission. The paraclinical data of the patients in our study is displayed in Table 3.

Table 2 Correlation of DAS28, age, education, hospital stay, and drug used in RA with 25(OH)D.

\begin{tabular}{lcc}
\hline Variable & r & P.value \\
\hline $\begin{array}{l}\text { DAS28 } \\
\text { a score } \\
\text { Mild }\end{array}$ & 0.122 & 0.671 \\
\hline \multicolumn{1}{c}{ Moderate } & -0.132 & 0.432 \\
\hline \multicolumn{1}{c}{ Severe } & 0.222 & 0.98 \\
\hline Age & -0.181 & 0.07 \\
\hline Education & 0.277 & 0.005 \\
\hline Disease duration & -.0408 & 0.0001 \\
\hline Drug used & -0.372 & 0.743 \\
\hline a: disease activity score \\
\hline
\end{tabular}


The results of Table 2 demonstrate a significant correlation among education levels and 25(OH)D $(P>0.01)$ which shows an increase in the serum levels of this vitamin with the increase of educational levels. Also, based on the assessment of the relationship between $25(\mathrm{OH}) \mathrm{D}$ 's serum levels and the duration of the disease, a significant correlation was obtained ( $P$ value: 0.0001 , correlation coefficient: -.0408); therefore, with an increase in the duration of the disease, $25(\mathrm{OH}) \mathrm{D}$ 's serum levels decreased.

Table 3 Paraclinical data of rheumatoid arthritis patients and their correlation with 25(OH)D serum levels.

\begin{tabular}{llcr}
\hline Laboratory test & Mean & correlation coefficient & P. value \\
\hline Anti CCP $(\mathrm{U} / \mathrm{ml})$ & 174 & 0.008 & 0.940 \\
$\mathrm{VAS}^{\mathrm{b}}(0-100)$ & 64.3 & 0.110 & 0.275 \\
\hline $\mathrm{DAS}^{\mathrm{c}} 8^{\mathrm{c}}$ & 3.48 & 0.588 & 0.383 \\
$\mathrm{RF}^{\mathrm{d}}$ & 11.18 & 0.139 & 0.169 \\
\hline $\mathrm{CRP}^{\mathrm{e}}$ & 7 & 0.394 & 0.246 \\
\hline
\end{tabular}

${ }^{a}$ : anti-cyclic citrullinated peptide; ${ }^{b}$ : visual analog scale; ${ }^{c}$ : disease activity score; ${ }^{d}$ : rheumatoid factor; ${ }^{\text {e }}$ C-reactive protein

As to the association of laboratory data and $25(\mathrm{OH}) \mathrm{D}$, no significant correlation was obtained (Table 3 ). Our variables were evaluated based on gender and the data are shown in Table 4.

Table 4 Association of variables based on gender $(n=100 ;$ male $=25$; female $=75)$

\begin{tabular}{|c|c|c|c|c|}
\hline ıriable & Gender & Mean & Standard deviation & $\mathbf{P}$ \\
\hline \multirow{2}{*}{$j(\mathrm{OH}) \mathrm{D}^{\mathrm{a}}$} & Male & 25.27 & 15.71 & 0.292 \\
\hline & Female & 23.80 & 21.85 & \\
\hline \multirow{2}{*}{ ti-CCP } & Male & 208.20 & 570.11 & 0.667 \\
\hline & Female & 163.42 & 441.31 & \\
\hline \multirow[t]{2}{*}{$\mathrm{FC}$} & Male & 16.56 & 28.17 & 0.02 \\
\hline & Female & 9.38 & 6.99 & \\
\hline \multirow[t]{2}{*}{$\overline{A S^{d}}$} & Male & 66.80 & 30.51 & 0.903 \\
\hline & Female & 63.46 & 29.88 & \\
\hline \multirow[t]{2}{*}{$4 S 28^{e}$} & Male & 3.39 & 1.36 & 0.420 \\
\hline & Female & 3.51 & 1.16 & \\
\hline \multirow[t]{2}{*}{$\overline{P^{f}}$} & Male & 6.24 & 5.86 & 0.686 \\
\hline & Female & 7.25 & 6.56 & \\
\hline
\end{tabular}

25-hydroxyvitamin $\mathrm{D} ;{ }^{\mathrm{b}}$ : anti-cyclic citrullinated peptide; ${ }^{\mathrm{c}}$ : rheumatoid factor ${ }^{\mathrm{d}}$ : visual analog scale; ${ }^{\mathrm{e}}$ : disease activity score; $^{\mathrm{f}}$ : reactive protein

As demonstrated in Table 4, there was only a significant relationship between RF levels and gender $(P>0.05)$. 
The relationship between the 25(OH)D's serum levels based on the location of residence was also evaluated using T-test. For urban areas, an average of $23.20(\mathrm{SD}=21.2)$ was obtained, while for rural areas an average of 27.41 (SD:17.57) was obtained. No substantial association was seen between the location of residence and serum levels of $25(\mathrm{OH}) \mathrm{D}(\mathrm{T}=0.866, \mathrm{P}=0.724)$.

\section{Discussion}

Hypovitaminosis D has been associated to autoimmune disease including RA in various studies [6]. Moreover, it was considered as a prognostic and reflective factor of disease activity. Anti-CCP and RF, on the other hand, were confirmed as diagnostic and also prognostic serum markers in RA patients. Therefore, the correlation between RA and vitamin D as well as its relationship with the mentioned autoantibodies separately prompted us to investigate if there is any significant correlation between the RA-related autoantibodies and 25(OH)D. Interestingly, we found no substantial association between Hypovitaminosis D and the foregoing serum markers. Thus, the lack of an appropriate amount of vit. D may not affect autoantibodies-dependent prognosis.

In this study, $73 \%$ of our sample population were classified as vit. D deficient. Haque et al. reported a favorable result which was $63 \%$. Therefore, the levels below optimal vit. D can be considered as a predisposing factor in developing RA features in susceptible patients, and routine administration of vit. D as a cheap and safe supplement should be well-thought-out. Rennie et al. also recommended that vit. D supplement intake reduces the severity of RA symptoms.

This study showed no significant relationship between DAS28 score and vit. D levels which indicate the disease activity VAS score; in other words, the number of swollen and tender joints, inflammatory blood markers (e.g., ESR and CRP) and patient's assessment of healthiness as well as pain self-assessment were not dependent on vit. D metabolites level.

Several experiments have shown that there is no correlation between the level of $25(\mathrm{OH}) \mathrm{D}$ and the activity of the disease [21]. Findings suggesting an opposite correlation between vitamin D metabolite levels and disease activity are contentious [22,23]. In a cross-sectional sample of 206 patients, Patel et al. found that each 10-ng / $\mathrm{ml}$ rise in the 25(OH)D level was correlated with a 0.3 decrease in the DAS28 score [24]. Despite lack of general association between vitamin D levels and DAS28, Higgins et al. claimed that, in the presence of vitamin D deficiency, patients could view themselves or be viewed by assessors as having reacted poorly to disease adjustment. He also offered evidence that the VAS factor is inversely linked to vitamin $D$, measuring the patient's understanding of symptoms, with lower levels delivering higher VAS values [25].

Based on our findings, we detected an inverse relationship between RA disease duration and vit. D levels. Chandrashekara et al. reported in a parallel study that patients with vit $\mathrm{D}$ deficiency had a prolonged duration of disease [26], while Haque et al. and Higgins et al. did not find any relationship between the disease duration and vit. D metabolites $[23,25]$. Lower levels of $25(\mathrm{OH}) \mathrm{D}$ over time may be related to functional and physical disability in RA patients followed by low exposure to sunlight and, therefore, a 
decrease in the level of vit. D metabolites. Patients with a greater period of sickness could also have had a worse diet or reduced exposure to sunshine.

In this report, we also revealed no significant correlation of vit. D metabolites level with inflammatory factors including CRP. Conversely, Kerr, et al. polemically, introduced the anti-CCP antibody positivity and higher CRP concentrations, as the associated factor for the higher risk of vit. D deficiency [27]. Every 10$\mathrm{ng} / \mathrm{ml}$ improvement in the 25(OH)D level was correlated with a 25 percent reduction in the CRP level, as reported by Patel et al. [24] In a similar study among 55 patients with RA, serum 25(OH)D levels were significantly negatively correlated with CRP levels [28]. Furthermore, Chandrashekar et al. found a significant improvement in CRP levels following vit. D supplement consumption [26]. Nevertheless, there are controversial results on investigating the relationship between 25(OH)D and some inflammatory serum factors; further evaluation of RA patients considering various stages should be performed.

There are few studies that assess the relationship of plasma 25(OH)D levels with autoantibodies which are related to RA such as anti-CCP and RF in patients diagnosed with RA. We found no association between vit. D levels with anti-CCP and RF, regardless of the severity and duration of disease. Feser et al. also indicated the absence of a substantial relationship between vit. D metabolites level and the mentioned autoantibodies which are in accordance with our results [29] Anaparti et al. and Yanan et al. described an inverse relationship between vit. D and anti-CCP [30,31]. Controversially, Herly et al. declared a significant positive association between vit. D and anti-CCP. [32] A positive association was also reported by Anaparti et al. between RF and vit. D levels [30]. It seems that vit D deficiency does not affect the higher titer of RA autoantibodies, but further studies with larger samples are required to confirm this result.

Many studies have focused on the association of vit. D and demographic variables; however, in our study, no significant correlation was obtained between vit D levels and variables including age, gender, and living location. Haque et al. confirmed the lack of correlation between sex and vit. D levels [23]. Whereas there are several studies which proved significant differences in vitamin D levels concerning gender. The difference in 25(OH)D levels according to gender was attributed to sex-related hormones [33,34]. Other studies also did not report any significant correlation as per age [35,23]. Furthermore, there was no defined relationship between hypovitaminosis D and living location [36]. Further studies with larger sample size are needed to assess the mentioned variable

It has been shown that there is an inverse association between vit. D level and educational status. On this account, the higher the educational level, the lower the vit. D level. Forrest et al. and Patel et al. also confirmed the negative correlation of the vit D level with educational status, as a marker of low socioeconomic status [37,24]. Lower socioeconomic status can also impact food choices among a minority of the populations and subsequently result in choosing less vit D rich foods such as fish. It is suggested that informing the society can reduce the incidence of vit. D deficiency.

There were some limitations in our study. It is possible that patients with longer disease duration had a worse diet or less sunlight exposure, so lower levels of $25(\mathrm{OH}) \mathrm{D}$ are reported by them. The second 
limitation was difficulty to precisely explain the causal relationships due to the fact that the study was cross-sectional.

As a conclusion, Vitamin D associated metabolites levels do not seem to be associated with the existence of RA-related autoantibodies such as RF and Anti CCP in RA patients. Furthermore, no significant correlation between serum inflammatory markers including CRP and vit D levels was found. Although there are no definitive results determining the exact ratio of 25(OH)D to disease activity or RA-related serum markers, evidence was found about the association of $25(\mathrm{OH}) \mathrm{D}$ and disease duration. Considering the levels below normal of $25(\mathrm{OH}) \mathrm{D}$ in a large number of cases $(73 \%), 25(\mathrm{OH}) \mathrm{D}$ should be checked in those patients.

\section{Declarations}

\section{Acknowledgement:}

The authors would like to thank Shiraz University of Medical Sciences, Shiraz, Iran and also Center for Development of Clinical Research of Nemazee Hospital and Dr. Nasrin Shokrpour for editorial assistance.

\section{Funding}

No financial support was received for this case report.

\section{Conflicts of interest}

The authors declare that they have no conflict of interest.

\section{Availability of data and materials}

SPSS data of the participant can be requested from the authors. Please write to the corresponding author if you are interested in such data.

\section{Code availability}

Not applicable

\section{Ethics approval and consent to participate}

Written informed consent was obtained from the patients in our study. The purpose of this research was completely explained to the patients and were assured that their information will be kept confidential by the researcher. This research was approved by the ethical committee of Shiraz University of Medical Sciences.

\section{References}


1. Cojocaru M, Cojocaru IM, Silosi I, Vrabie CD, Tanasescu R (2010) Extra-articular manifestations in rheumatoid arthritis. Maedica 5 (4):286 -291

2. Gibofsky A (2014) Epidemiology, pathophysiology, and diagnosis of rheumatoid arthritis: Am J Manag Care. 20 (7 Suppl):S128-135

3. Turesson C, Jacobsson L (2004) Epidemiology of extra-articular manifestations in rheumatoid arthritis. Scand J Rheumatol. 33 (2):65-73. https ://doi.org/10.1080/03009740310004621.

4. Lee $D$, Schur $P$ (2003) Clinical utility of the anti-CCP assay in patients with rheumatic diseases. Ann Rheum Dis. 62 (9):870-874. https ://doi.org/ 10.1136/ard.62.9.870.

5. Kastbom A, Strandberg G, Lindroos A, Skogh T (2004) Anti-CCP antibody test predicts the disease course during 3 years in early rheumatoid arthritis (the Swedish TIRA project). Ann Rheum Dis. 63 (9):1085-1089. https ://doi.org/ 10.1136/ard.2003.016808.

6. Cantorna MT, Mahon BD (2004) Mounting evidence for vitamin D as an environmental factor affecting autoimmune disease prevalence. Exp. Biol. Med. 229 (11):1136-1142. https://doi.org/ $10.1177 \% 2 \mathrm{~F} 153537020422901108$

7. Griffin MD, Lutz W, Phan VA, Bachman LA, McKean DJ, Kumar R (2001) Dendritic cell modulation by 1a, 25 dihydroxyvitamin $D 3$ and its analogs: a vitamin $D$ receptor-dependent pathway that promotes a persistent state of immaturity in vitro and in vivo. Proc Natl Acad Sci U S A. 98 (12):6800-6805. https ://doi.org/ 10.1073/pnas.121172198.

8. Helming L, Böse J, Ehrchen J, Schiebe S, Frahm T, Geffers R, Probst-Kepper M, Balling R, Lengeling A (2005) 1a, 25-dihydroxyvitamin D3 is a potent suppressor of interferon $y$-mediated macrophage activation. Blood. 106 (13):4351-4358. https ://doi.org/ 10.1182/blood-2005-03-1029

9. Azzeh FS (2012) Relationship between vitamin D and rheumatoid arthritis disease. Pak J Nutr. 11 (3):293-300

10. Merlino LA, Curtis J, Mikuls TR, Cerhan JR, Criswell LA, Saag KG (2004) Vitamin D intake is inversely associated with rheumatoid arthritis: results from the lowa Women's Health Study. Arthritis Rheum. 50 (1):72-77. https://doi.org/10.1002/art.11434

11. Saag KG (2004) Vitamin D intake is inversely associated with rheumatoid arthritis. Arthritis Rheum. 50(1):72-77. https://doi.org/10.1002/art.11434

12. Rossini M, Bongi SM, La Montagna G, Minisola G, Malavolta N, Bernini L, Cacace E, Sinigaglia L, Di Munno O, Adami S (2010) Vitamin D deficiency in rheumatoid arthritis: prevalence, determinants and associations with disease activity and disability. Arthritis Res. Ther. 12 (6):R216

13. Ercan A, Cui J, Chatterton DE, Deane KD, Hazen MM, Brintnell W, O'Donnell Cl, Derber LA, Weinblatt ME, Shadick NA (2010) Aberrant IgG galactosylation precedes disease onset, correlates with disease activity, and is prevalent in autoantibodies in rheumatoid arthritis. Arthritis Rheum. 62 (8):2239-2248

14. Arnett FC, Edworthy SM, Bloch DA, Mcshane DJ, Fries JF, Cooper NS, Healey LA, Kaplan SR, Liang MH, Luthra HS (1988) The American Rheumatism Association 1987 revised criteria for the classification of rheumatoid arthritis. Arthritis Rheum. 31 (3):315-324. https ://doi.org/ 10.1002/art.1780310302 
15. Soubrier M, Lambert C, Combe B, Gaudin P, Thomas T, Sibilia J, Dougados M, Dubost J-J (2018) A randomised, double-blind, placebo-controlled study assessing the efficacy of high doses of vitamin $D$ on functional disability in patients with rheumatoid arthritis. Clin Exp Rheumatol. 36 (6):1056-1060

16. Wewers ME, Lowe NK (1990) A critical review of visual analogue scales in th.e measurement of clinical phenomena. Res Nurs Health. 13 (4):227-236. https ://doi.org/ 10.1002/nur.4770130405.

17. Feng X, Ye T, Wang Z, Chen X, Cong W, Chen Y, Chen P, Chen C, Shi B, Xie W (2016) Transcutaneous acupoint electrical stimulation pain management after surgical abortion: A cohort study. Int J Surg. 30:104-108. https ://doi.org/ 10.1016/j.ijsu.2016.04.042

18. Thaxton L, Pitotti J, Espey E, Teal S, Sheeder J, Singh RH (2018) Nitrous Oxide Compared With Intravenous Sedation for Second-Trimester Abortion: A Randomized Controlled Trial. Obstet Gynecol. 132 (5):1192-1197. https ://doi.org/ 10.1097/AOG.0000000000002915

19. Rezvani Amin M, Siratinayer M, Abadi A, Moradyan T (2011) Correlation between visual analogue scale and short form of McGill questionnaire in patients with chronic low back pain. Qom UMSJ. 5 (1):31-34

20. Dhir V, Goyal P (2014) Poor accuracy of anti-citrulline antibody test in diagnosis of rheumatoid arthritis in Iran. Rheumatol Int. 34 (4):591-591. https ://doi.org/ 10.1007/s00296-013-2739-7

21. Sahebari M, Mirfeizi Z, Rezaieyazdi Z, Rafatpanah H, Goshyeshi L (2014) 25 (OH) vitamin D serum values and rheumatoid arthritis disease activity (DA S28 ESR). Caspian J Intern Med. 5 (3):148-155

22. Cutolo M, Otsa K, Laas K, Yprus M, Lehtme R, Secchi M, Sulli A, Paolino S, Seriolo B (2006) Circannual vitamin $D$ serum levels and disease activity in rheumatoid arthritis: Northern versus Southern Europe. Clin Exp Rheumatol. 24 (6):702-704

23. Haque UJ, Bartlett S (2010) Relationships among vitamin D, disease activity, pain and disability in rheumatoid arthritis. Clin Exp Rheumatol. 28 (5):745-747

24. Patel S, Farragher T, Berry J, Bunn D, Silman A, Symmons D (2007) Association between serum vitamin $\mathrm{D}$ metabolite levels and disease activity in patients with early inflammatory polyarthritis. Arthritis Rheum. 56 (7):2143-2149. https ://doi.org/ 10.1002/art.22722.

25. Higgins M, Mackie S, Thalayasingam N, Bingham S, Hamilton J, Kelly C (2013) The effect of vitamin D levels on the assessment of disease activity in rheumatoid arthritis. Clin Rheumatol. 32 (6):863867. https ://doi.org/ 10.1007/s10067-013-2174-x

26. Chandrashekara S, Patted A (2017) Role of vitamin D supplementation in improving disease activity in rheumatoid arthritis: An exploratory study. nt J Rheum Dis. 20 (7):825-831. https ://doi.org/ 10.1111/1756-185X.12770

27. Kerr GS, Sabahi I, Richards JS, Caplan L, Cannon GW, Reimold A, Thiele GM, Johnson D, Mikuls TR (2011) Prevalence of vitamin D insufficiency/deficiency in rheumatoid arthritis and associations with disease severity and activity. J Rheumatol. 38 (1):53-59. https ://doi.org/ 10.3899/jrheum.100516.

28. Turhanoğlu AD, Güler H, Yönden Z, Aslan F, Mansuroglu A, Ozer C (2011) The relationship between vitamin $D$ and disease activity and functional health status in rheumatoid arthritis. Rheumatol Int. 31 (7):911-914. https ://doi.org/ 10.1007/s00296-010-1393-6. 
29. Feser M, Derber LA, Deane KD, Lezotte DC, Weisman MH, Buckner JH, Mikuls T, O’DELL J, Gregersen PK, Holers VM (2009) Plasma 25, OH vitamin D concentrations are not associated with rheumatoid arthritis (RA)-related autoantibodies in individuals at elevated risk for RA. J Rheumatol. 36 (5):943946. https ://doi.org/ 10.3899/jrheum.080764.

30. Anaparti V, Meng X, Hemshekhar M, Smolik I, Mookherjee N, El-Gabalawy H (2019) Circulating levels of free $25(\mathrm{OH}) \mathrm{D}$ increase at the onset of rheumatoid arthritis. PLoS One. 14 (9):e0219109. https ://doi.org/ 10.1371/journal.pone.0219109.

31. Yanan W, Zhang F, Shanshan W, Shang X, Siyuna L, Hongjuan Z, Huaping S, Long C (2016) Serum vitamin $D$ level is inversely associated with anti-cyclic citrullinated peptide antibody level and disease activity in rheumatoid arthritis patients. Arch Rheumatol.31 (1):64-70. https ://doi.org/ 10.5606/ArchRheumatol.2016.5556.

32. Herly M, Stengaard-Pedersen K, Vestergaard P, Østergaard M, Junker P, Hetland ML, Hørslev-Petersen K, Ellingsen T (2018) The D-vitamin metabolite 1, $25(\mathrm{OH})$ 2D in serum is associated with disease activity and Anti-Citrullinated Protein Antibodies in active and treatment naïve, early Rheumatoid Arthritis Patients. Scand J Immunol. 88 (3):e12704. https ://doi.org/10.1111/sji.12704.

33. Crescioli C, Minisola S (2017) Vitamin D: autoimmunity and gender. Curr Med Chem. 24 (24):26712686. https ://doi.org/ 10.2174/0929867323666161220105821.

34. Vasile M, Corinaldesi C, Antinozzi C, Crescioli C (2017) Vitamin D in autoimmune rheumatic diseases: a view inside gender differences. Pharmacol Res. 117:228-241. https ://doi.org/ 10.1016/j.phrs.2016.12.038.

35. Sirbu E, Buleu F, Tudor A, Dragan S (2020) Vitamin D and disease activity in rheumatoid arthritis patients: a retrospective study in a Romanian cohort. Acta Biochim Pol. 67 (2):267-272. https ://doi.org/10.18388/abp.2020_5360.

36. Gannagé-Yared MH, Chemali R, Yaacoub N, Halaby G (2000) Hypovitaminosis D in a sunny country: relation to lifestyle and bone markers. J Bone Miner Res. 15 (9):1856-1862. https ://doi.org/10.1359/jbmr.2000.15.9.1856.

37. Forrest KY, Stuhldreher WL (2011) Prevalence and correlates of vitamin D deficiency in US adults. Nutr Res. 31 (1):48-54. https ://doi.org/ 10.1016/j.nutres.2010.12.001. 